\title{
NEW INTERPRETATION OF CRUSTAL EXTENSION EVIDENCES ON MARS
}

\author{
E. A. Grin \\ Laboratoire "Physique du Systeme Solaire" \\ Observatoire de Meudon, 92195 Meudon, France
}

\begin{abstract}
Summary
The record of early evolution of life on Earth has been obscured by extensive surface activity. On the opposite, large fractions of the martian surface date back to an early clement epoch favorable to the needs of biological systems [1]. The upper martian surface reflects a wide variety of modifying processes which destroy the geological context. However, due to endogenic causes acting after the end of the primordial bombardment, abundant extensional structures display vertical sequences of stratigraphic units from late Noachian to early Hesperian periods [2]. Deep structural incisions in the upper crust provide unaltered strata, open flanks, and slope deposits that favor the use of an autonomous landerrover-penetrator [3] that can perform geological investigations simultaneous with a biological search for fossils from various epochs.
\end{abstract}

The strategy for an exobiology search of such an optimum site should be guided by the recent attention devoted to extensional structures and their global significance [4]. Geological evidence supporting the martian crustal extension is suggested by abundant fractures associated with the dichotomy boundary northland-south upland, i.e., Aeolis Region, and peak igneous activity (Elysium bulge). As pointed out by [5], the system of fractures correlates with the endogenic origin of the dichotomy, as related to a major difference in the thickness of the crust. Perpendicular to this boundary, fractures of deep graben testify to a general tectonic crust relaxation. The opening of the graben, joined with compressive wrinkles, is the signature of a dynamical pervasive stress regime that implies a large scale roll-over of the upper crust over the ductile interface of a more dense mantle. This general motion is not a transport of material, as there is no thickening on the boundary of the dichotomy. The horizontal movement is due to the gravitational mechanism and differential thermal convection cells in the upper crust over the slope of the anti-flexure rigid interface consequential to Elysium bulge. The fracturation occurs as the neutral zone of the crust rises to the brittle surface of the crust. Deep extensional structures are logical sites for locating and sampling fossilized organisms from various epochs. Grabens suggest ancient lakes and the development of biological systems supported by bottom hot springs.

\section{References:}

(1) Cabrol N. (1989), Lunar Planet S. XX, p. 135

(2) McGille (1988), NASA TM, p. 549.

(3) Friedmann E. (1987), Space Life Proc.

(4) Morgan P. (1983), Tectonophysics 94, p. 1.

(5) McGille (1989), J. Geophys. Res. 